\title{
Clinical \& pathological correlation between SARS-CoV-2 infection with coexisting health conditions: A review
}

\author{
Rituparna Saha $^{\mathrm{a}, \mathrm{b}}$, Mainak Mukhopadhyay ${ }^{\mathrm{a}}$, Debalina Bhattacharya ${ }^{\mathrm{c}}$ \\ ${ }^{a}$ Department of Biotechnology, JIS University, Agarpara, West Bengal 700109. \\ ${ }^{b}$ Department of Biochemistry, University of Calcutta, Ballygunge, West Bengal 700019. \\ ${ }^{\mathrm{c}}$ Department of Microbiology, Maulana Azad College, Taltala, West Bengal 700013. \\ *Corresponding Author: Debalina Bhattacharya \\ E-mail Address: debalina.bhattacharya13@gmail.com
}

\begin{abstract}
Globally, the COVID-19 pandemic has brought the world to a standstill with the infected cases surpassing millions. The causative agent of COVID-19, the SARS-CoV-2 is a novel coronavirus that emerged from the wet animal market in Wuhan, China in early December 2019. Soon after, human-to-human transmission increased the rate of infection making the disease widespread with new hotspots emerging around the world.

The epidemiological reports based on clinical characteristics including age, gender, symptoms (both severe and non-severe), and the conditions requiring intensive medical care, along with case fatality revealed that people with co-existing health conditions like diabetes, hypertension, cigarette smoking, and others with cardiovascular and kidney diseases were more susceptible to COVID-19 infection with poor prognosis in cases related to the severity of symptoms and requiring ICU, medical ventilators with a high fatality rate. Even people with immunosuppressed conditions like HIV and cancer, alongwith old age and pregnant women are vulnerable to COVID-19 infection and can cause severe health complications.

It is extremely important to have a comprehensive idea of the underlying pathophysiology related to these health conditions which makes them more susceptible to contract SARSCoV-2 infection in correlation with the development of severe symptoms. This review will provide an extensive viewpoint related to COVID-19 patients having coexisting health conditions together with the association between the prognosis of the disease and the pathogenesis of the SARS-CoV-2 infection, based on the current information available.
\end{abstract}

Keywords: COVID-19, SARS-CoV-2, Comorbidities, Clinical characteristics, Pathobiology, 2019-nCov.

\section{Introduction}

The World Health Organization (WHO) led by the alarming levels of the spread of COVID19 (Coronavirus Disease - 2019) across countries and severity of infections, along with added inaction taken by the governments to combat the disease, assessed to characterize COVID-19 as a pandemic [1]. According to the Johns Hopkins University COVID-19 database, at the time of writing, the number of globally confirmed cases stands close to reaching millions in 188 countries and regions $[2,3]$. Around the world, this pandemic is wreaking havoc affecting over two-thirds of the population, with most of the countries going into lockdown, shuttingoff schools, universities, and government and private offices, and banning air-travel, to stop human-to-human transmission and overwhelming the health-care system [4].

The first infected cases of the novel coronavirus ( $\mathrm{nCoV}$ ) were reported out of Wuhan, China in December of 2019, where clusters of patients suffering from an unidentified form of viral pneumonia were hospitalized with the majority having a common travel history of visiting the Huanan sea-food market [5]. This alerted the Chinese Center for Disease Control and 
Prevention (China CDC) which upon collecting the patients' samples and testing them utilizing cell cultures and whole-genome sequencing, identified the virus to belong to the genus of betacoronavirus, and subsequently having high sequence similarity to another previously identified coronavirus $(\mathrm{CoV})$ which causes Severe Acute Respiratory Syndrome (SARS) [6,7]. This led the China CDC to name the nCoV as SARS-CoV-2, with WHO naming the disease as COVID-19 and declaring it to be a Public Health Emergency of International Concern by early February 2020 [8].

In comparison to previously identified Coronaviruses and the diseasescaused by them like SARS and Middle-East Respiratory Syndrome (MERS), COVID-19 is transmitted from human-to-human through respiratory fomites and has a reported reproductive number $\left(\mathrm{R}_{0}\right)$ between 2 and 3.5, indicating one infected person could transmit the disease to two to three people [9]. The common spectrum of symptoms shown by patients is similar to flu and includes consistent dry cough, fever, and shortness of breath and, in some cases, severe pneumonia [10]. The total number of infected cases for COVID-19 has already surpassed the total cases of SARS and MERS combined, with a case fatality rate (CFR) of approximately $2 \%$, which is much lower in comparison to SARS and MERS which had a CFR of about $10 \%$ and $34 \%$, respectively [11].

Despite the low CFR, an early trend was reported from clinical and epidemiological studies based on COVID-19 patients in China, which has been getting repeated as the pandemic is spreading globally $[12,13]$. Based on the first 425 cases reported from the city of Wuhan, about $56 \%$ were male with the median age of patients infected was found to be 59 years. The elderly populations were highly vulnerable with higher mortality and morbidity rates especially among those with coexisting health conditions $[14,15]$. By mid-February, China CDC building on 44,672 confirmed cases reported the $\geq 80$ age group to have the highest fatality rate at $14.8 \%$. Males had a CFR of $2.8 \%$ in comparison to $1.7 \%$ in females. Also, patients with existing health conditions were reported to have a much higher CFR with $10.5 \%$ among those having cardiovascular disease, $7.3 \%$ for those with diabetes, $6.3 \%$ for chronic respiratory illness, whereas $6 \%$ and $5.6 \%$ for hypertension and cancer patients, respectively $[16]$.

Based on these reports, a comprehensive understanding is required to focus on the correlation between the SARS-CoV-2 infection to the vulnerable population and the people with comorbid conditions.

\section{SARS-CoV-2 - Infection mechanism \& Pathogenesis}

The causative agent of COVID-19, SARS-Cov-2 is the third betacoronavirus to have emerged in the past two decades. They are mostly zoonotic, meaning they get transmitted from animals to humans, with SARS and pneumonia as the most prominent symptoms observed in patients infected with the virus [17].Genome sequencing and electron microscopy studies have shown SARS-CoV-2 to have higher sequence homology with SARS-CoV and morphologically similar with other coronaviruses in shape and size, enveloping a positive single-stranded RNA, and containing spike glycoprotein, membrane glycoprotein and nucleocapsid protein [18].

Between SARS-CoV and SARS-CoV-2, the spike proteins share a 76.5\% amino acid sequence similarity with an almost identical receptor-binding domain [19]. This has led to the identification of the functional SARS-CoV receptor i.e. the human angiotensin-converting enzyme 2 (ACE2) as the receptor for SARS-CoV-2, which helps in facilitating the entry of the virus into host cells and replicate effectively (Fig. 1). Analysis has shown SARS-CoV-2 recognizes ACE2 more efficiently and has a higher binding affinity, which increases its ability to transmit between humans [20,21]. 

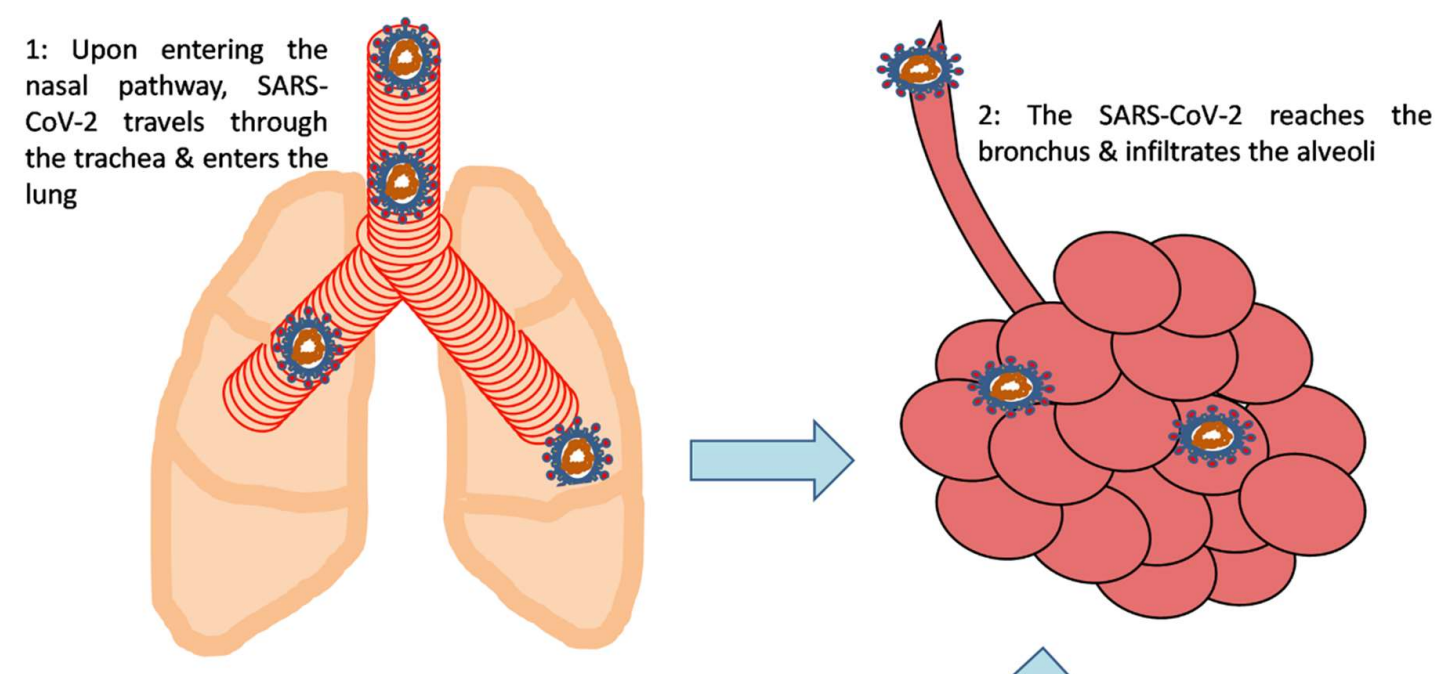

3: After which, the SARS-CoV2 spike protein binds to the ACE2 receptors expressed by the AECII

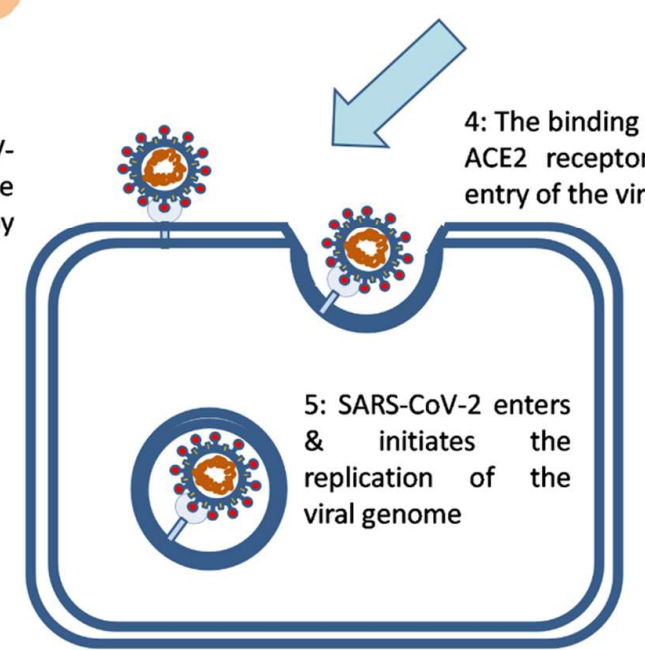

Figure 1: Pathogenesis associated with SARS-CoV-2 Infection in Human Lung

1: Upon entering the nasal pathway, SARS-CoV-2 travels through the trachea and enters the lung

2: The SARS-CoV-2 reaches the bronchus and infiltrates the alveoli

3: After which, the SARS-CoV-2 spike protein binds to the ACE2 receptors expressed by the type II alveolar epithelial cells (AECII)

4: The binding of SARS-CoV-2 to ACE2 receptors facilitates the entry of the virus into the cells

5: SARS-CoV-2 enters and initiates the replication of the viral genome

Zhao et al. [22] studied the expression of ACE2 through the newly developed single-cell RNA sequencing technology and found that on average $83 \%$ of ACE2-expressing cells are type II alveolar epithelial cells (AECII), predominant in lung tissue, thus making it a key factor as to the increased susceptibility of the lung to COVID-19. This could help to explain the higher rate of infection in men as they have a higher percentage of ACE2 receptors present in their alveolar cells as compared to women [23]. Also, gene ontology enrichment analysis between AECII populationshave established that these cells have multiple viralprocess genes, which aids in the viral life cycle, assembly, and maintaining positive regulation in different viral processes and its replication, thus promoting the quantitative replication of the coronavirus in the lung [22]. 
Further studies into the expression of the SARS-CoV-2 receptor ACE2 found its presence in extrapulmonary tissues like heart, kidney, intestinal epithelial cells, and endothelium, which might explain the multi-organ dysfunction that is increasingly observed in patients. A detailed investigation into the expression and mechanism of ACE2 receptors in intestinal epithelial cells and the gut epithelium could also help to understand the implication of viral transmission through two major ways - one, consumption of infected food and second, a probable fecal-oral pathway [24].

\section{Effect of COVID-19 in population with co-existing health conditions}

Amid this COVID-19 pandemic, a stark trend has been emerging. Though most of the individuals who get infected with the virus get mild symptoms and recover without requiring any form of intensive medical care. But some individuals develop severe symptoms and experience pneumonia or move towards multi-organ failure if not provided with intensive medical support, on time.As per the epidemiological studies getting reported from the countries where the disease is at its peak, it suggests that people with pre-existing medical conditions are at a higher risk of contracting the disease and their conditions worsen rapidly (Fig. 2). From what scientists have learned from Wuhan, China is that patients who were older and suffering from conditions like cerebrovascular and cardiovascular diseases required ICU more likely, with arrhythmia and acute cardiac injury among the most common complications found in patients requiring ICU care. CFR was also higher in patients with comorbidities as compared to those who have none $[25,26]$.

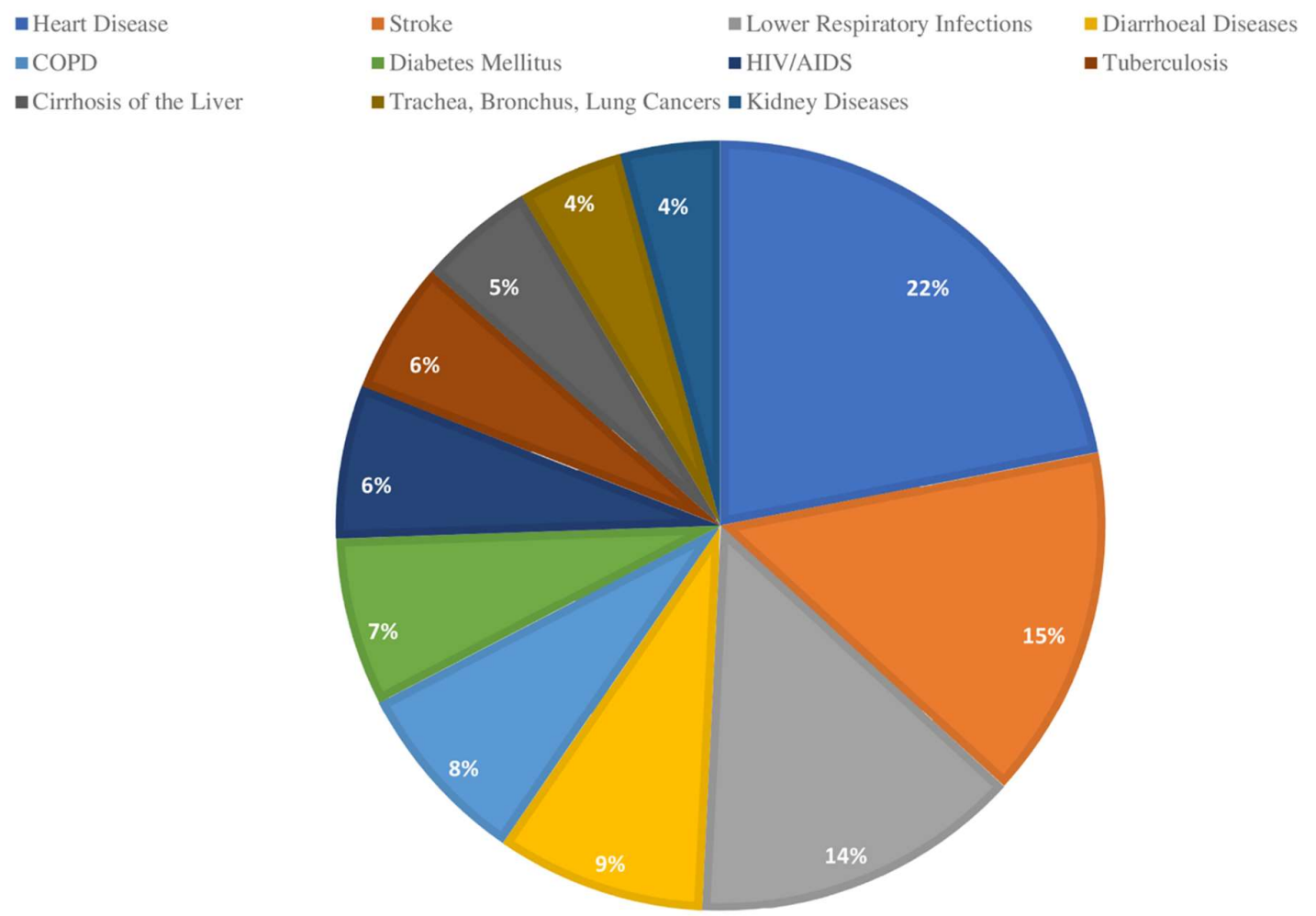

Figure 2: Global Statistics of Disease pre-disposition according to WHO, for the year 2016 [As per \% of Disability-Adjusted Life Years (DALYs) per 100,000 of the population] https://www.who.int/healthinfo/global_burden_disease/estimates/en/index1.html 
Thus, in the present scenario, it's highly important to understand the correlation between the infection mechanism of the virus and the pathobiology related tocomorbidities in patients.

\subsection{Diabetes}

According to WHO, diabetes is a chronic, metabolic disease-related with an elevated blood sugar level and which ultimately causes damage to blood vessels, kidney, heart, eyes, and nerves. Diabetes alone affects 422 million people worldwide aged 20-79 years old, with an aggregation of patients mostly in the middle- and low-income countries, and counts for more than 1.6 million deaths worldwide every year [27,28]. Therefore, it is most likely that a large population of diabetic patients will get affected by the ongoing COVID-19 pandemic as well. The early assessment into the transmission dynamics and epidemiological characteristics of the first 425 patients from Wuhan, China by Li et al. [15] suggested case definition including symptoms and critical care may vary accordingly in patients with comorbidities. This was proved to be true when the Chinese CDC reported the epidemiological characteristics of about 72,314 patients of which $61.8 \%$ were confirmed cases, with fatality rates of $7.3 \%$ in diabetic patients as compared to $0.9 \%$ in patients with no comorbid conditions [16]. Whereas, Liu et al. [29] reported a case study of 109 patients from the Central Hospital of Wuhan based on acute respiratory distress syndrome (ARDS) as a clinical characteristic in those patients, and found, in comparison to non-ARDS patients, patients who developed ARDS were like to have a co-existing health condition and were the most prominent symptom in diabetic patients with a rate as high as $20.8 \%$. Although there is insufficient evidence, still there might be a connection between mortality and diabetes, as is evident from the clinical data of 46 fatal cases, all from Hubei province. 29 out of the 46 patients had comorbidities, with diabetes accounted for $26.2 \%$ of them, only second to hypertension [30]. The rate of infection by the virus in diabetic patients had the same characteristic in cases reported from other provinces of China. A study led by Wang et al. [31] of 165 patients in the Fujian Province of China with a median age of 44 years and about $38.8 \%$ of the population had an underlying disease with diabetes forming $8.2 \%$ of the cluster. This scenario can be predicted to be highly similar to the epidemiological characteristics of other countries as well.

Most importantly diabetic patients have always shown a poor prognosis to viral infections like in seasonal influenza, H1N1 flu, SARS and MERS. One apparent reason for the severity between COVID-19 and diabetes could be the heavily compromised innate immune system which is the first line of defense, and is observed in patients with diabetes mellitus and with short-term hyperglycemia, thus making the virus to proliferate quickly without any form of hindrance. Another rationale between the association of diabetes and COVID-19 could be ACE2 receptors, a glycosylated protein present in both pulmonary and extrapulmonary epithelial cells and is responsible for the breakdown of angiotensin-I (Ang-I) and angiotensin-II (Ang-II), which gets gravely reduced in patients with diabetes mellitus probably due to glycosylation and could be the factor behind the increased lung injury and development of ARDS, under SARS-CoV-2 infection. This has proved to be a conundrum for scientists, cause the diabetic patients to use ACE inhibitors (ACEi) and angiotensin-receptor blockers (ARBs), which increases the expression of ACE2 receptors to regulate the elevated levels of Ang-I and Ang-II, but in turn could facilitate the entry of the SARS-CoV-2 virus in the host cells, without regulating the levels of Ang-I and II, increasing aldosterone secretion and subsequently increasing potassium loss through urine, giving rise to hypokalemia. And inadvertently increasing the severity of lung injury in COVID-19 due to the degradation of the ACE2 enzyme by the virus [32,33].

Potential treatments for diabetic patients suffering from COVID-19 may include good inpatient glycemic control with specialized glucose target goals ranging from mild to severe patients, alongwith subcutaneous insulin delivery therapy and intravenous insulin infusion 
therapy for patients who are critically ill. Maintaining blood glucose levels with inherent changes in strategies as the symptoms develop could help in the speedy recovery of the patients [34,35]. But, a more comprehensive experimental study is required in this regard for frontline workers for whom its quite difficult to strategize a patient-specific treatment in the current conditions.

\subsection{Hypertension}

Besides diabetes, hypertension was reported to be the major comorbidity present in COVID19 patients with the same clinical characteristics as patients with diabetes alongwith a high fatality rate. As per the study performed by Liu et al. [29] on 109 patients with a mean age of 55years, coexisting conditions were related to the development and severity of ARDS which included patients with hypertension (33.9\%) at a high proportion. Another report out of the Fujian Province in China, about $14.5 \%$ of patients had hypertension as a health condition in a cluster of 165 patients hospitalized with COVID-19 with the median age of 44 years [31]. As per the Chinese CDC, out of 44,672 confirmed cases, patients with hypertension had a mortality rate of $6.0 \%$ as compared to $0.9 \%$ in patients with no coexisting health conditions [16]. This equivalent to $40.5 \%$ (hypertension) of the fatality rate seen in patients with COVID-19 in the 29 of the first 46 fatal cases reported by the Chinese government from the Hubei province [30]. The scenario is similar to all the epidemiological reports coming out of different countries where people who have hypertension as a health condition are more susceptible to the SARS-CoV-2 virus and with COVID-19 develop severe symptoms requiring intense medical care.

Hypertension is clinically defined as a cardiovascular disorder where the patient experiences an elevated blood pressure level persistently. A specific characteristic of hypertension is its interrelatedness with type 2 diabetes, as patients suffering from hypertension are at a much higher risk of developing diabetes and vice-versa. The frequency of occurrence of these coexistent conditions varies accordingly with regards to racial, social and ethnic groups. The overlap of hypertension with diabetes in patients gives rise to complications that range from cardiovascular to chronic kidney disease and retinopathy [36,37]. As per the established epidemiological reports during COVID-19, there might be a chance the percentage of people with hypertension and diabetes that have contracted the virusand the fatality rate linked to these two types of comorbidities, may have overlapping conditions. There has been no mention of whether this was accounted for. Thus, while studying patient clusters in this pandemic it better to mention and report the kind of assessment characteristics the research group was trying to suggest.

As with diabetes, hypertension is also treated with ACEi and ARBs to increase the expression of ACE2 receptors. Sometimes, thiazolidinediones and ibuprofen are also used. Thus, increased expression of ACE2 receptors, as usual, could facilitate the entry and subsequent replication of the SARS-CoV-2 virus resulting in the development of severe symptoms like ARDS rapidly and the patients requiring intensive medical care. A reason behind this could be asserted from a study done by Chen et al. [38] on a cohort of 106 patients from Wuhan, China with comorbidities like diabetes and hypertension having COVID-19, took a long time for an effective viral clearance, and the usage of antivirals like Arbidol also did not have any effect, whereas cortisone, frequently used for SARS patients had a negative effect based on the results. Patients with hypertension and diabetes in COVID-19 infections generally have a poor prognosis and a high-risk factor with delayed viral clearance due to the expression of ACE2 receptors [33,39]. Thus, it can be suggested that the patients' conditions should be monitored with ACE2 modulating drugs and alternative medical therapy should also be developed by studying the mechanism of the viral infection in accordance with the ACE2 receptors in detail. 


\subsection{Cigarette Smoking}

Cigarette smoking and exposure to nicotine has become a global health hazard, affecting millions in the population, both male and female, and has always been related to poor prognosis in diseases, as tobacco has a negative impact on lung health and also, has been associated with a multitude of respiratory diseases [40]. Smoking has adverse effects on the immune system and its ability to respond to infections, thus leaving the smokers vulnerable to a range of infections. It is mainly this reason that makes smokers twice as likely to contract respiratory diseases like influenza, SARS, and MERS, and develop severe symptoms with a much higher fatality rate as compared to non-smokers [41].

Out of the epidemiological reports published during the COVID-19 pandemic, there isn't much evidence available as to the relation between smokers and COVID-19, with regards to the symptoms, severity of the disease and patients requiring intensive medical care. Although some studies made on the small cohorts could help to understand the clinical characteristics concerning smokers and COVID-19. Huang et al. [42] did a study on a small cluster of 41 patients admitted to the hospital in Wuhan, China; and had a median age of 49 years among which $73 \%$ were male with 3 non-ICU patients identified to be smokers, which is quite insignificant given the size of the group. Another group of 140 patients with a 1:1 male to female ratio and a median age of 57 years was studied by Zhang et al. [43] and found 6.4\% were smokers with 5\% making upto be past smokers and the rest current smokers. Concerning disease severity, all the current smokers had severe symptoms in comparison to only $6.9 \%$ of past smokers developing severe symptoms. Zhou et al. [44] reported findings from 191 patients with COVID-19 from Wuhan, China among which 54 didn't survive. Based on the clinical characteristics of the patients, a total of $11(6 \%)$ were current smokers, among which 6(4\%) survived and the rest didn't. A study of 545 patients from Wuhan, China by Shu et al. [45] with a median age of 50 years suffering from COVID-19 were characterized based on mild to moderate type of pneumonia, reported 122 cases with a history of smoking whereas 423 cases had no smoking history. To date, the most comprehensive data with a significant cluster of patients has been reported by Guan et al. [46], in which the group carried out the study of 1099 COVID-19 confirmed patients from around 522 hospitals in mainland China with the median age being 47 years with female patients making upto be $41.9 \%$.According to the clinical characteristics of the 172 patients who had severe symptoms, $16.9 \%$ were current smokers in comparison to $5.2 \%$ being former smokers. The 913 patients who didn't develop severe symptoms, $11.8 \%$ were current smokers to $1.3 \%$ being former smokers. Whereas among the patients who needed ICU, ventilation or died $25.8 \%$ were current smokers and $7.6 \%$ were former smokers, and the patients who didn't require any of the intense medical care $11.8 \%$ were current smokers and $1.6 \%$ were former smokers. The clinical outcome of the severity of COVID-19 present in smokers to non-smokers must be related to the pathophysiological changes that occur in the lung that has been regularly exposed to nicotine.

Cigarette smoking has always been linked to a range of pulmonary and cardiovascular diseasesdue to the expression of various types of nicotinic receptors in the lung, blood vessels and cardiac tissueand the adverse effects those receptors have on the surrounding normal cells. In the case of COVID-19 infection, the virus gets a probable advantage from the nicotinic receptors which take over the regulation of ACE2 protein expression in the cells. The exposure to nicotine causes the alteration in expression of ACE2 protein by the lung AT2 cells, causing an upregulation of ACE2 in the entire epithelium cell layer present in the airway. A change to the immune system in the pulmonary tissue is brought about by cigarette smoking by activating the inflammatory cytokines and programmed cell death and acting directly on the circulating $\mathrm{T}$ cells, causing irreparable lung damage. This may lead to an enhanced exposure of the lung tissues of smokers to the SARS-CoV-2 virus, causing its 
immediate attachment to the cell surface of ACE2 without any form of immune mechanisms, making the cells highly susceptible to the virus which can remain tagged to the host cells for a longer period. This leads to an active proliferation of the virus, which can then have the ability to mutate and ultimately modify the host immune mechanism, making the host an efficient carrier of the virus for future infection and spread. Experiments with in vivo knockout mice models have shown that when SARS-CoV-2 binds with the ACE2 receptors, it greatly down-regulates the expression of ACE2 protein and increases the other related ACE family of proteins. This change in the modulation of ACE2 expression could lead to acute respiratory failure [47-49].

Cigarette smoking (current, former or non-smoker) as a dataset for COVID-19 remains highly understudied, though if thoroughly characterized, over half the world population will fall into the current or former smoking category. Now, with the introduction of e-cigarettes, more people can be counted for inclusion in this category. It is important to learn the prognosis of COVID-19 in smokers, the severity of the symptoms as well as the fatality rate. WHO and all the other countries should make it mandatory to include a COVID-19 patients' smoking status including severity or non-severity of the symptoms, patients requiring intensive medical care, with the rate of death. With this pandemic, the datasets of smoking individuals could help to understand how nicotine exposure and consumption are related to virus-infected illnesses, which could help the health officials to identify the vulnerable populations and help with providing intervention.

\subsection{Chronic Respiratory Disease}

Respiratory diseases are one of the most common comorbidity after diabetes and hypertension in COVID-19 patients. Several factors have led to an increase in the frequency of respiratory diseases among the general population. Smoking is one of the etiological factors which give rise to chronic obstructive pulmonary disease (COPD) [48]. Together withother respiratory conditions like asthma, tuberculosis, and acute lung infections, they are currently the fourth leading cause of death in the world. Studies have suggested people with respiratory diseases are more susceptible and vulnerable to contracting respiratory viral infections with the development of severe symptoms and high mortality.

Clinical characteristics of COVID-19 patients studied by Guan et al. [46] of 1099 patients from 30 provinces in mainland China, with a median age of 47 years observed $1.1 \%$ to have COPD as comorbidity, with $3.5 \%$ developing severe symptoms and $10.4 \%$ requiring some sort of intense medical care like ICU, mechanical ventilation, or have died. Zhang et al. [43] reported the clinical characteristics of 140 patients out of Wuhan, China with a median age of 57 years. They reported 2 patients $(1.4 \%)$ each had secondary pulmonary tuberculosis and COPD as a comorbidity with all of them showing severe symptoms of COVID-19. The percentage is almost similar to the report by Guan et al., but both the population had its percentage of smokers, both current and former, who also developed severe COVID-19 symptoms but no correlation of the symptoms with patients who were smokers and those who had COPD were suggested.As per China CDC which released records of 72,314 COVID-19 patients - the epidemiological study reports $2.4 \%$ of patients suffering from chronic respiratory diseases as a coexisting condition, with a case fatality rate of $6.3 \%$ [16], although they didn't classify the respiratory diseases into COPD and others.

People with respiratory illness are more at risk of contracting SARS-CoV-2 virus because of the altered physiology of the lung which includes an imbalance of the lung microbiota, systemic mucus production, structural damage, impaired host immunity with alterations in local and/or systemic inflammatory response, and the regular use of corticosteroids [50]. These alterations might also be responsible for the development of severe symptoms when people contract the SARS-CoV-2 virus. Also, increased expression of ACE2 levels in the 
lung as a result of comorbidity heightens the risk of infection, as ACE2 is the identified receptors for the SARS-CoV-2 virus [39,51]. Thus, people with respiratory illnesses should take preventive measures from exposure to the SARS-CoV-2 virus and from those who are either suspected or confirmed patients of COVID-19. Doctors should also make an effort to provide useful information to their patients suffering from respiratory illnesses amid this pandemic, and should also monitor COVID-19 patients and their symptoms especially those who are suffering from this comorbidity to fully understand the implications COVID-19 could have on patients with respiratory illnesses.

\subsection{Cardiovascular Disease}

Coexisting cardiovascular diseases (CVD) in COVID-19 patients has quickly become a prominent risk factor with disease severity and high mortality rate, in comparison to diabetes and hypertension.CVD accounted for $4.2 \%$ of COVID-19 patients with a CFR as high as $10.5 \%$ in a cohort of 72,314 cases reported by the China CDC [16]. The percentage of CVD reported is almost at par with Wang et al. [31] whose epidemiological data of 165 patients from the Fujian Province in China also showed CVD as a comorbidity in $4.8 \%$ patients, though with no mention of symptoms severity and CFR in this population of patients. Similar to Zhang et al. [43] whose study of 140 COVID-19 patients from Wuhan, China found CVD in $5 \%$ of patients with symptoms severity in only $3.7 \%$ of them. In comparison, the clinical characteristics of 1099 COVID-19 patients studied by Guan et al. [46] showed only $2.5 \%$ of them had CVD as a coexisting condition with 5.8\% developing severe symptoms and about $9 \%$ requiring some form of intensive medical care. The percentage of CVD as comorbidity and poor prognosis of the disease in an epidemiological study depends upon the median age and demography of the population considered, as the prevalence of CVD greatly increases with old age especially in people over 65 years.

The preliminary clinical diagnosis involved in SARS-CoV-2 infection is mostly respiratory symptoms, but as the disease progresses the virus can cause severe damage to the cardiovascular system even in patients with no comorbidity. This is evident from the case reported by Inciardi et al. [52] in which they studied the cardiac complications that arose in an otherwise healthy 53-year-old COVID-19 patient whose biochemical data included elevated levels of N-terminal pro-brain natriuretic peptide (NT-proBNP) and cardiac Troponin (cTn) which are all sensitive markers for myocardial injury, upon which the patient was treated for heart failure. No evidence of any coexisting CVD was found in the angiography. To date, no presence of SARS-CoV-2 RNA has been reported in the cardiovascular system. A probable reason for cardiac involvement in COVID-19 could be that the virus upon replication in the lung travels via the blood or the lymphatic system, or the myocardial injury could be the result of an exaggerated inflammatory response triggered by SARS-CoV-2.

The susceptibility of the cardiovascular system to SARS-CoV-2 infection in patients with no comorbidity makes CVD patients much more at risk for disease severity and high mortality. A cross-sectional study made by Chen et al. [53] on 150 COVID-19 patients reported that increased levels of NT-proBNP and cTn are prevalent in male patients with hypertension and CVD, in especially critical cases as compared to mild ones, underlying a significant correlation between levels of NT-proBNP and cTn with CVD and severity of COVID-19.

The severity of the symptoms observed in patients with CVD could be a result of increased expression of ACE2 enzyme in the lung and heart tissue, as it plays an important role in maintaining heart function in the cardiovascular system. Just like in diabetes and hypertension, ACEi and ARBs are recommended heavily for CVD patients, which might be a determining factor for the increased susceptibility to the SARS-CoV-2 virus which has a high affinity for ACE2 receptors [54]. But according to the study made by Peng et al. [55] on 112 
COVID-19 patients, with all having CVD as comorbidity, no significant correlation could be established with the dosage of ACEi and ARBs medication between the severe and nonsevere patients and also between those who survived and those who didn't. A positive difference was reported with biochemical tests like lymphocyte count, BMI, and NT-proBNP and lactic acid levels in terms of critical and non-critical cases, which could further be correlated with the aggravating symptoms and the cause of death. In comparison, ACEi and ARBs did not affect the development of severe symptoms and mortality. Thus, the exact mechanism underlying the effect of SARS-CoV-2 infection on the cardiovascular systemis still unknown. So, importance should be given to the identification of CVD, if present, in a COVID-19 patient given his age, and required treatment should be made to avoid the development of severe symptoms related to the cardiovascular system.

\subsection{Cerebrovascular Disease}

The implications of SARS-CoV-2 infection and its disease prognosis in patients suffering from cerebrovascular diseases has not been fully acknowledged and understood.Epidemiological studies and clinical characteristics taking account of cerebrovascular diseases as a comorbidity in COVID-19 patients have been too few and far between.Although, a significant effect of the SARS-CoV-2 virus on the nervous system could be observed from the prevalence of clinical symptoms like headache, nausea and/or vomiting. As per the study conducted by Mao et al. [56], the manifestations of neurological symptoms in COVID-19 patients were reported in 214 patients with $7 \%$ having the cerebrovascular disease as comorbidity. Diagnosed by two neurologists, $24.8 \%$ patients showed symptoms constituting the central nervous system (CNS) (including dizziness, headache, impaired consciousness, acute cerebrovascular disease, ataxia, and epilepsy) with $30.7 \%$ severity, $8.9 \%$ patients showed symptoms affecting the peripheral nervous system (including hypogeusia, hyposmia, hypopsia, and neuralgia) with $8 \%$ severity, and $23 \%$ developing skeletal muscle injury with $19.3 \%$ severity.Still, no underlying correlation has been yet established as to the difference in the progression and severity of COVID-19in patients with coexisting cerebrovascular disease as compared to normal and other comorbid conditions.

The epidemiological study performed by Guan et al. [46] on 1099 patients suffering from COVID-19,reported symptoms of headache in $13.6 \%$ patients with $15 \%$ showing disease severity, whereas nausea or vomiting was present in $5 \%$ with $6.9 \%$ showing severity. This study also reported cerebrovascular diseases as a comorbidity in $1.4 \%$ of the patients with $2.3 \%$ showing disease severity and $6 \%$ of the patients requiring some sort of intense medical care like ICU or mechanical ventilation. Besides, Liu et al. [29] investigated the development of ARDS in 109 patients suffering from COVID-19. The patients didn't show initial symptoms like headache, nausea or vomiting, but about $5.5 \%$ of patients were reported to have a cerebrovascular disease as a comorbidity with all of them developing ARDS throughout the disease.Although these studies didn't acknowledge the mortality related to cerebrovascular patients with COVID-19, it can be implied that this group is highly susceptible to SARS-CoV-2 infectionand with the rate of the severity of COVID-19 observed, it can also be suggested that patients of this group show a poor prognosis of the disease and thus, a more detailed study should be made to better understand the pathogenesis of SARS-CoV-2 on the nervous system.

To understand the invasive potential of a virus, the most common method is to identify the receptors which the virus has an affinity for and the tissues where the receptors are mostly distributed. But, the presence of receptors is not solely responsible to increase the susceptibility of the host cells to the virus. Previous studies with SARS-CoV have found the virus in some cells which didn't have any detectable levels of ACE2 receptors. Similarly, the infection of SARS-CoV and MERS-CoV has been present in the CNS, where the viral 
particles have been found in the neurons. Though the exact route through which the virus travels in the CNS has not been identified, evidence suggests that CoVs may first enter the peripheral nerve terminals and through trans-synaptic transfer, gains access to the CNS [57]. Therefore, the similarity between SARS-CoV and SARS-CoV-2 could help to better understand the neuroinvasive potential of the virus and to identify the extent of SARS-CoV-2 infectionin the nervous system and the underlying pathobiology related to it.

\subsection{Chronic Kidney Disease}

Impairment of kidney functions with a manifestation of renal failure and probable development of chronic kidney disease (CKD) is highly prevalent in adult patients, especially in older people with a wide range of severity in symptoms. But,forSARS-CoV-2 infection and its implication in people with CKD, valuable scientific information is still limited.

Epidemiological data of different demography and prognosis of COVID-19 in patients with coexisting CKD reveals there is a high risk of severity involved with old age. Wang et al. [31] reported the presence of CKD in $2.4 \%$ patients out of 165 , suffering from COVID-19 with all of them being $\leq 65$ years of age. Similarly, Zhang et al. [43] found CKD in $1.4 \%$ patients among 140 with a median age of 64 years, and with all of them developing severe symptoms. Liu et al. [29] studied the progression and development of ARDS in COVID-19 patients and found 8 out of 10 patients with coexisting CKD, developed ARDS and had a median age of 61 years. Guan et al. [46] studied 1099 COVID-19 patients, and reported 3 out of $8(0.7 \%)$ patients with coexisting CKD, developed severe symptoms with 2 of them requiring intensive medical care. Though the mortality rate was not assessed, it can be well implicated that patients with CKD as comorbidity are highly susceptible and shows poor disease prognosis for SARS-CoV-2 infection.

One way to understand the extent of kidney impairment in COVID-19 patients is to assess the various biochemical features related to the diagnosis of any type of kidney dysfunction. Cheng et al. [58] conducted a study on a cohortof 710 COVID-19 patients with a median age of 63 years, to examine the rate of acute kidney injury associated with kidney impairment. Based on biochemical tests, $44 \%$ and $26.9 \%$ had proteinuria and hematuria respectively, with elevated levels of serum creatinine found in $15.5 \%$ and blood urea nitrogen in $14.1 \%$. The prevalence of kidney impairment among the patients was found relatively high with the rate of mortality found to be $12.3 \%$. The major drawback of this study is the lack of information regarding the presence of $\mathrm{CKD}$ as a comorbidity in these patients. Also, the patients were relatively admitted in the later stage of the infection during which the disease has already become severe leading to a high rate of death. Thus, it's difficult to analyze epidemiological study as there might be a chance that the development of severe symptoms in the patients has led to widespread failure in kidney function or it may be the result of the combined effect of CKD and SARS-CoV-2 infection which led to the aggravation of kidney impairment and dysfunction.

Establishing the association of SARS-CoV-2 infection with kidney impairment in patients with and without CKD requires a systemic evaluation.Li et al. [59] performed a study among 128 non-severe COVID-19 patients, 65 severe COVID-19 patients and a control group of 28 patients suffering from other types of viral pneumonia. On diagnosis, a relatively high fraction of patients showed signs of kidney dysfunctions including proteinuria $(59 \%)$, hematuria $(14 \%)$ alongwith elevated levels of serum creatinine $(10 \%)$ and blood urea nitrogen (14\%). But, these were highly prevalent in COVID-19 patients ranging from mild to worse, as compared to patients suffering from other types of pneumonia. The cases of kidney dysfunction gradually worsened as the SARS-CoV-2 infection progressed and ultimately turned into acute kidney injury (AKI). COVID-19 patients with AKI had an increased mortality rate, almost $\sim 5.3$-times higher than in patients who didn't develop AKI. Therefore, 
its highly mandatory for clinicians to keep on monitoring kidney functions in COVID-19 patients day-to-day, and take precautionary steps to avoid AKI and possible renal failure.

Recent findings suggest that in addition to the alveolar cells in the lungs, ACE2 receptors are also expressed in extrapulmonary tissues like heart, kidney and the gut. And the effect that SARS-CoV-2 infection has on these organs like cardiac injury, abdominal pain, and AKI, implies the virus has a viable tropism for these organs. But, whether the viral replication takes place in these organs which causes the probable injury and spreads through the body, is not yet fully understood [60]. The other possible reason could be that kidney dysfunctionis a result of inflammatory reactions followed by lung impairment [59]. Thus, to fully apprehend the effect of SARS-CoV-2 infection with the expression of ACE2 receptors in the kidney and the underlying correlation to lung inflammation, a more detailed investigation is required. And a fundamental analysis is required in terms of the morbidity and mortality related to CKD in COVID-19 patients.

\section{Others}

\subsection{Digestive Diseases}

The implications and disease prognosis of COVID-19 patients suffering from pre-existing digestive diseases remains unknown. There have been very few epidemiological reports in which digestive diseases have been accounted for as a comorbidity in COVID-19 patients. Two important reasons as to the relevance of digestive diseases in patients contracting the virus are - one, the presence of the ACE2 receptors in extrapulmonary tissues like the gut epithelium and bile duct, and second, diarrhea, nausea, and/or vomiting is the early symptoms attributed to whether a patient is suffering from COVID-19. The knowledge of digestive diseases in a COVID-19 patient could help to correlate the clinical characteristics with regards to the severity of the symptoms and liver abnormalities associated with the digestive tract and treat accordingly.

As per the few epidemiological reports available in which digestive diseases are included as comorbidity, very little could be established as to the relation between the onset of the symptoms and the progress of the disease with the physiology of the digestive diseases. $\mathrm{Wu}$ et al. [61] reported the clinical characteristics of a cohort of 80 patients with a median age of 46.1 years from Jiangsu Province in mainland China. All of them had mild to moderate symptoms with 3 patients having digestive system disease and 1 reported to have chronic liver disease. Laboratory findings revealed 3 patients with alanine transaminase (ALT) or aspartate aminotransferase (AST) levels above the normal range. Whereas 2 patients showed lower albumin levels, as a part to assess their liver function. But whether these patients belonged to the digestive disease and liver disease comorbidity group, or developed liver function abnormality as a result of COVID-19 is not mentioned. Another study led by Yang et al. [62] on 149 patients from Wenzhou city, Zhejiang, China with 8 (5.37\%) patients were reported to have coexisting digestive system diseases, and $11(7.38 \%)$ patients developed diarrhea and $2(1.34 \%)$ patients developed nausea and vomiting as symptoms. But, whether these patients included those who had digestive diseases or was there was any form of overlapping of these notable symptoms in those same patients remain unreported. As per liver function is concerned $12.08 \%$ and $18.12 \%$ of patients showed high levels of ALT and AST respectively, whereas $6.04 \%$ of patients showed decreased levels of albumin. But again, if these patients included those with coexisting digestive diseases or were there any relation between patients showing vomiting, nausea, and diarrhea as symptoms of developing abnormalities in their liver function was not evaluated.

The digestive system could potentially become a pathway for transmitting and contracting the virus. The presence of ACE2 receptors in the digestive system could harbor the SARS-CoV-2 virus and help it to replicate. There has been evidence of the SARS-CoV-2 RNA in tissue 
samples collected from the stomach, duodenum, and the rectal mucosa [63]. A study led by $\mathrm{Hu}$ et al. [64] on three patients suggested SARS-CoV-2 can persist in the gastrointestinal tract much longer than the respiratory tract. They detected viral nucleic acids in anal swab samples and stool samples in COVID-19 patients, who developed and didn't developed any form of gastrointestinal symptoms, long after the virus was not detected in the respiratory tract. Autopsy reports may also help to understand the effect of COVID-19 on the digestive system. So far, the autopsy of an 85-year-old COVID-19 patient revealed segmental dilation and stenosis present in the small intestine [65]. But it is not known whether the complication arose from a combinatorial effect of coexisting digestive disease and COVID-19 or just severity of COVID-19 symptom alone.

Extensive strategies are needed to be implemented to understand the potential risk and the development of symptoms in COVID-19 patients with coexisting digestive diseases and treat accordingly. Also, the type of digestive disease and its existing pathology should be mentioned in the epidemiological reports in correlation with COVID-19 symptoms.

\subsection{Tuberculosis}

According to WHO, in 2018 an estimated 10 million people worldwide including men, women, and children, fell ill with tuberculosis (TB) andremains one of the leading causes of death from an infectious agent to this day. Multidrug-resistant TB (MDR-TB) has become a persistent public health crisis and poses a health security threat. Another multi-layer threat posed by TB is the high vulnerability and susceptibility of people with HIV (Human Immunodeficiency Virus) to contract TB, making a lethal combination. In 2018, an estimated more than half a million cases were reported with TB among HIV-positive people, of which almost $72 \%$ were in Africa [66].

Many of the African countries are the worst hit nations with infectious diseases, and human resources and their health care system are already spread thin [67]. Some of the countries are still coping with the Ebola epidemic. With the emergence of COVID-19 in the African countries, experts speculate that it is highly mandatory to contain the spread of the infection at its earlier stages. Many countries in Africa have already reported a surge of COVID-19 infections, with more than half of them are identified to be imported cases. To date, no epidemiological reports have emerged as to the morbidity and mortality of SARS-CoV-2 infection in patients with coexisting TB. But, it can be predicted that with both of the diseases being mostly lung based infections, TB patients will be highly vulnerable to SARS-CoV-2 infection, especially patients who have overlapping HIV with TB. Plus, with new infections of TB always emerging in the poorest communities, it will be quite a challenge for the clinicians to differentiate one infection from another. And with their health care systems running low on medical supplies and test kits, COVID-19 can have a devastating impact on the population.

Social distancing measures are the only way to avoida massive wave of infections hitting the already strained health care systems in the African countries. But with a large number of people living in temporary shelters and close quarters, alongwith sharing common water supply and washrooms, it will be very difficult to achieve frequent hand washing and selfisolation for people who are the most vulnerable in these conditions [68]. Thus, it will be of paramount importance for clinicians and health workers to inform the communities adequately according to their circumstances, and thorough identification of COVID-19 symptoms and testing is mandatory to separate and quarantine the patients early on.

\subsection{HIV}

In 2018, WHO estimated a whopping 37.9 million people living with HIV worldwide, with two-thirds of those infected living in the African region. People with HIV are highly 
susceptible to TB, and if remains undetected can prove fatal. Overtime, TB has become one of the leading causes of death in people with HIV, with TB associated 1 out of 3 HIV-related deaths. Although there is no cure for HIV, antiretroviral therapy (ART) has proved to be quite effective in controlling the virus, along with achieving suppression to reduce transmission to other people [69].

Epidemiological reports of COVID-19 patients infected with HIV alongwith the disease prognosis related to the morbidity and mortality of SARS-CoV-2 infection have been rare. Zhu et al. [70]reported a unique case of a 61-year old man from Wuhan, who tested positive for COVID-19. The man was a heavy smoker with coexisting diabetes and showed symptoms of high fever, dry cough and shortness of breath, which got worse as the disease progressed and thus, he was kept on supplemental oxygen. Based on biochemical tests, he was diagnosed with mild lymphomenia which also got worse alongwith a low CD4+ T-lymphocyte percentage of $4.75 \%$, which led to the detection of HIV upon a positive antigen/antibody combination test. As per the regulations provided by the Chinese authority, the man was treated with combinatorial antiviral drugs. After about 15 days of treatment, the patient tested negative for COVID-19 and was released from the hospital, and was instructed to stay in selfisolation for two weeks. There are multiple limitations to this study, including a lack of follow up to his HIV condition. Plus, it is difficult to relate the disease prognosis of COVID19 in a patient already affected with HIV and undergoing ART. The case reported by Zhu et al. could very well serve as a base level study and an initial form of treatment method in COVID-19 patients infected with HIV.

It's difficult to predict the effect COVID-19 will have on HIV patients, especially in the African population where HIV is endemic. Though the average age of the African population is invariably young, its vulnerability and susceptibility to COVID-19 will take a toll on the already strained healthcare system and the weak economy, where a large portion of the population have a hand to mouth existence [71]. Therefore, it is upto the government to take immediate mitigating measures and educate the people about social distancing, prevention measures, and self-isolation, especially for those infected with different diseases like TB, HIV, and others.

\subsection{Cancer}

The COVID-19 pandemic has provedto be an insurmountable challenge to oncologists and cancer patients. The immunosuppressed conditions of the cancer patients due to their disease pathogenesis and ongoing treatments, making them highly susceptible to SARS-CoV-2 infection. The most common symptoms which are observed in COVID-19 patients are mostly fever, cough, and shortness of breath, whereas nausea, vomiting, diarrhea, and headache form some of the other reported symptoms too. These same symptoms are also seen in cancer patients after chemotherapy, and also for targeted and immune therapy, alongwith increased vulnerability to pneumonia and respiratory infections due to their low immunity [72]. In these unprecedented times, the doctors must make decisions about how to balance the treatment of cancer patients to minimize exposure to SARS-CoV-2 infection, then what to do for the patients especially elderly patients, who are under constant care in times of social distancing measures and how to provide adequatemedical care to cancer patients when the healthcare system is already strained because of COVID-19 patients [73].

Epidemiological reports and clinical characteristics of COVID-19 patients suffering from cancer provides a rather grim picture related to the morbidity and mortality of the disease in cancer patients. An early study made by Guan et al. [46] on 1099 COVID-19 patients, observed 3 cancer patients showed severe symptoms among 10 patients with one patient requiring intensive medical care. Liang et al. [74] reported a study of 18 cancer patients out of 1590 COVID-19 patients, with lung cancer being the most frequent $(28 \%)$, while $25 \%$ had 
some sort of treatment or surgery in the recent past and another $25 \%$ was made up of cancer survivors. The cancer patients had a mean age of 63.1 years with most of them developing severe symptoms and a majority of them requiring intensive medical care like ICU and mechanical ventilators, with patients who had recently received chemotherapy or surgery being at greater risk. Zhang et al. [75] also studied a cohort of 28 COVID-19 patients from Wuhan, China, all suffering from cancer, with lung cancer being the most common. The patients had a median age of 65 years, with $26.8 \%$ of patients suspected to get SARS-CoV-2 infection via hospital transmission. Severe cases were significantly high with $53.6 \%$ showing deteriorating conditions and rate of mortality being $28.6 \%$. Though all these studies provide an effective viewpoint, their epidemiological reports have limitations with regards to the small percentage of COVID-19 patients with a variety of cancer, thus effectively lacking to represent the cancer population [76]. Plus, different types of cancer have a variety of pathobiology related to them, while patients at different stages of cancer can also represent a different population altogether, with some under-current treatment and some under total remission.

Amidst this pandemic, clinicians need to take effective measures for providing medical help to cancer patients. Delaying treatments like radiotherapy which forms one of the most common modes of treatment for cancer patients, can reduce its combinatorial effect in patients, and in some cases, may prove to be fatal [77]. Thus, healthcare workers should strategize according to the needs of the cancer patients, and prioritize accordingly. Some highly constructive policies could be made to provide cancer care, if possible, by reducing onclinic visits and issue information and counseling through remote care, and providing effective communication to first responders and caregivers who come in contact with cancer patients, and switching from systemic to oral administration of treatments, which will greatly minimize visitation of patients to hospitals [78,79].

\subsection{Organ Transplant Patients}

The transplant community faces an insurmountable challenge in the form of the COVID-19 pandemic. Organ donors, organ recipients and patients with organ transplants are at major risk to contract SARS-CoV-2 infection because of their immunosuppressed conditions. Meanwhile, formerly planned organ transplant operations can get delayed due to the overwhelming conditions of the health-care system, which might prove to be fatal in patients who have underlying health conditions.

Epidemiological reports of transplant patients contracting SARS-CoV-2 infection have been sparse, but a few available studies in a wide variety of transplant patients provide a reasonable viewpoint into the clinical outcome of COVID-19 infection. Huang et al. [80] studied the progress of COVID-19 in two post-transplantation cases - a 59-year old recipient who had a renal transplant and a 51-year old recipient who had allogenic bone marrow transplant. Both of the patients were under immunosuppressed therapy and had the transplant before getting SARS-CoV-2 infection. After they tested positive for COVID-19, their immunosuppressive treatment was discontinued and a combinatorial treatment containing methylprednisolone with prophylactic antibiotics wascommenced. Both the patients had extremely low levels of $\mathrm{T}$ cells, alongwith developing severe symptoms and then died, despite being under mechanical ventilation. $\mathrm{Li}$ et al. [81] reported the first two cases of COVID-19 in heart transplantation patients - a 51-year old man who had a heart transplant in 2003 and was under immunosuppressive treatment the whole time. The patient had a cardiac allograft, whose function was normal alongwith controlled hypertension. Upon showing symptoms of fever, chills, fatigue, and diarrhea, he was admitted to the hospital whereupon he testedpositive for COVID-19. He was treated intravenously and required supplemental oxygen, and with that, his conditions stabilized and symptoms improved. He was then treated 
orally and after 20 days of remaining in the hospital tested negative for COVID-19. Another 43-years old heart transplant patient who showed mild symptoms and tested positive for COVID-19 was quarantined at home. After his quarantine period, he was admitted to the hospital following which he was tested for COVID-19 and was found to be negative. Both of these studies report the disease prognosis of COVID-19 in transplant patients. Whereas, recipients and donors are at risk too, and can get infected by SARS-CoV-2 through hospital transmission. Qin et al. [82] report a diagnosis of COVID-19 in a recipient of a liver transplant under perioperative condition. The patient showed improvement in lung condition after intensive treatment, but still suffered from prolonged fever, lymphomenia and liver function instability. Under the current scenario, it has become immensely paramount to test for COVID-19 in both donor and recipient, in every step of the procedure. If COVID-19 remains unrecognized in a recipient, it might cause severe immunosuppressive conditions leading to multiple organ failure and death. Whereas in donors, unchecked COVID-19 may lead to the spread of infections to multiple recipients. Therefore, strict guidelines should be developed to screen for COVID-19 in donors and recipients and, organ transplant patients to implement the correct treatment procedure early on. And they should also be kept under an extended follow up even after the COVID-19 infection.

Another clinical problem related to organ transplant patients is that under immunosuppressive conditions, the patient might present atypical symptoms of various diseases. In that case, there is a high potential the clinician might treat the patient for known viral infections unless tested for COVID-19. Guillen et al. [83] reported COVID-19 infection in a kidney transplant patient, whose initial symptoms were gastrointestinal viral disease and fever, which further developed to respiratory distress within 48 hours and was under mechanical ventilation at the time of the study. It is of great importance that screening for COVID-19 must be performed for all transplant patients coming to the hospital for health issues. Some people might be asymptomatic or some even suffer from symptoms unrelated to COVID-19, making timely detection and proper therapeutic intervention mandatory in transplant patients.

\section{Effect of COVID-19 in the vulnerable population}

With the emergence of COVID-19 infection worldwide, epidemiological reports and clinical characteristics have very well implied the risk factors of patients with underlying health conditions. Comorbidities proportionately increase the susceptibility of patients to SARSCoV-2 infection alongwith developing a poor disease prognosis. In comparison to people with comorbidities, another cohort has come to represent a vulnerable population which includes pregnant women, children, and older people.

COVID-19 might prove to have serious consequences during pregnancy, due to the constant immunosuppressive condition a pregnant woman is in throughout the three trimesters, making vertical transmission to the fetus a cause for concern [84]. Epidemiological data concerning COVID-19 in pregnant women have been limited with no possible cases of vertical transmission has been reported as of yet, though more evidence is needed to develop potential strategies for prevention and treatment [85]. The disease prognosis of SARS-CoV-2 infection in pregnant women has been the same as in non-pregnant women, in relation to morbidity and mortality. Still, a more detailed study encompassing a large cohort of pregnant women suffering from COVID-19 with long term follow up is required for clinicians to better understand the implications of this infectious disease during pregnancy [86].

Children suffering from COVID-19 has been uncommon, with the development and manifestation of symptoms being mild to moderate. Qiu et al. [87] identified 36 children suffering from COVID-19, with most of them having mild symptoms like fever and dry cough. Many were cured with oral treatments while some needed supplemental oxygen. They were kept in the hospital for a mean average of 14 days. Though the cohort was small, still a 
large proportion of the children were asymptomatic, indicating the difficulty of clinicians to identify them unless tested and the ability of the children to become a mode of transmission for SARS-CoV-2 infection in the community. Another concern that pediatricians have is for children with underlying comorbid conditions, which may lead to the development of severe symptoms as they do in adults [88]. Hence, more research-based evidence is required for COVID-19, so that parents and doctors can take effective measures in terms of prevention and early treatment methods.

The most vulnerable population to COVID-19 is perhaps the elderly people, with a CFR of $8 \%$ in those aged between $70-79$ years and $14.8 \%$ in patients 80 years or older, in a total of 72,314 cases, as reported by the China CDC [89]. One of the many reasons is the high percentage of people in the higher age bracket mostly have a coexisting illness and in some cases, suffer from multiple diseases, becoming a high-risk factor for SARS-CoV-2 infection. The other condition is their weak immunity which becomes more fragile with age, increasing their susceptibility to COVID-19.Other issues include the increased expression of ACE2 protein in patients who regularly uptake ACEi and ARBs due to their coexisting conditions, and also, as some researchers predict, the antibody-dependent enhancement could happen in patients who have been exposed to other coronaviruses previously [90].

Therefore, clinicians and healthcare workers should take special measures and mitigate policies under COVID-19, to provide professional and medical help in this time of social distancing, to the people who are the most vulnerable and susceptible to SARS-CoV-2 infection and COVID-19.

\section{Future Outlook}

The COVID-19 pandemic has upended our daily lives and has laid bare the crisis in our healthcare system and our incompetency to handle such a pandemic. For years, scientists have been alerting our leaders about the possibility of such an occurrence and to plan out effective measures to be deployed, should a pandemic like this ever occur. Scientists have now estimated that COVID-19 will probably infect $60-70 \%$ of the world population, as the pandemic runs its course through 10-12 months before a vaccine is developed.

Over the last two decades, the world has faced three epidemics, all arising from zoonotic viruses, the SARS, MERS, and Ebola, though they mostly have been limited to specific regions. The increase in the frequency of these zoonotic viruses getting transmitted from animals to humans could be for a variety of reasons. One probability could be that rapid industrialization and economic development had led to heavy deforestation, increasing the contact between humans and animals. With the loss of biodiversity, the human-animal conflict is rapidly escalating, making it possible for such viruses to come into contact with humans. With humans capturing, killing or even consuming more bush meat, it is highly likely that the frequency of such occurrences will increase.

COVID-19 has become a great leveler as it affects both developed and developing countries alike; thus, making it subsequently important for us to learn from our mistakes, change human behavior, and work towards making responsible mitigation policies and improve the conditions of our healthcare system, and start educating the general public about prevention and awareness.

Funding: No funding received.

Conflicts of Interest: The authors have no conflicts of interest to declare. 


\section{Reference:}

1. WHO

Coronavirus disease (COVID-19) situation reports. Situation report - 51. https:/www.who.int/docs/default-source/coronaviruse/situation-reports/20200311sitrep-51-covid-19.pdf?sfvrsn=1ba62e57 4, Accessed 11 March 2020

2. JHU

Coronavirus Resource Center https://coronavirus.jhu.edu/map.html, Accessed 25 March 2020

3. Remuzzi A, Remuzzi G. COVID-19 and Italy: what next? The Lancet 2020. https://doi.org/10.1016/S0140-6736(20)30627-9

4. Velavan TP, Meyer CG. The COVID-19 epidemic. TM \& IH 2020;25:278-280. https://doi.org/10.1111/tmi.13383

5. Lauer SA, Grantz KH, Bi Q, Jones FK, Zheng Q, Meredith HR, Azman AS, Reich NG, Lessler J. The Incubation Period of Coronavirus Disease 2019 (COVID-19) from publicly reported confirmed cases: Estimation and application. Ann Intern Med 2020. https://doi.org/10.7326.M20-0504

6. Sohrabi C, Alsafi Z, O’Neill, Khan M, Kerwan A, Al-Jabir A, Iosifidis C, Agha R. World Health Organization declares global emergency: A review of the 2019 novel coronavirus (COVID-19). Int Surg J 2020;76:71-76. https://doi.org/10.1016/j.ijsu.2020.02.034

7. Peeri NC, Shrestha N, Rahman MS, Zaki R, Tan Z, Bibi S, Baghbanzadeh M, Aghamohammadi N, Zhang W, Haque U. The SARS, MERS and novel coronavirus (COVID-19) epidemics, the newest and biggest global health threats: what lessons have we learned? Int J Epidemiol 2020;1-10. https://doi.org/10.1093/ije/dyaa033

8. Lai C, Shih T, Ko W, Tang H, Hsueh P. Severe acute respiratory syndrome coronavirus 2 (SARS-CoV-2) and coronavirus disease-2019 (COVID-19): The epidemic and the challenges. Int J Antimicrob Agents 2020;55:105924. https://doi.org/10.1016/j.ijantimicag.2020.105924

9. Anderson RM, Heesterbeek H, Klinkenberg D, Hollingsworth TD. How will countrybased mitigation measures influence the course of the COVID-19 epidemic? The Lancet 2020;395:931-934. https://doi.org/10.1016/S0140-6736(20)30567-5

10. Zu ZY, Jiang MD, Xu PP, Chen W, Ni QQ, Lu GM, Zhang LJ. Coronavirus Disease 2019 (COVID-19): A perspective from China. Radiology 2020. https://doi.org/10.1148/radiol.2020200490

11. Mahase E. Coronavirus: COVID-19 has killed more people than SARS and MERS combined, despite lower case fatality rate. BMJ 2020;368. https://doi.org/10.1136/bmj.m641

12. Bedford J, Enria D, Giesecke J, Heymann DL, Ihekweazu C, Kobinger G, Lane HC, Memish Z, Oh M, Sall AA, Schuchat A, Ungchusak K, Wieler LH. COVID-19: towards controlling of a pandemic. The Lancet 2020. https://doi.org/10.1016/S01406736(20)30673-5

13. Onder G, Rezza G, Brusaferro S. Case-Fatality rate and characteristics of patients dying in relation to COVID-19 in Italy. JAMA 2020. https://doi.org/10.1001/jama.2020.4683

14. Fauci AS, Lane HC, Redfield RR. Covid-19 - Navigating the uncharted. N Engl J Med 2020;382:1268-1269. https://doi.org/10.1056/NEJMe2002387

15. Li Q, Guan X, Wu P, Wang X, Zhou L, Tong Y, Ren R, Leung KSM, Lau EHY, Wong JY, Xing X, et al. Early transmission dynamics in Wuhan, China, of novel Coronavirus-Infected Pneumonia. N Engl J Med 2020;382:1199-1207. https://doi.org/10.1056/NEJMoa2001316 
16. The Novel Coronavirus Pneumonia Emergency Response Epidemiology Team. The epidemiological characteristics of an outbreak of 2019 Novel Coronavirus Disease (COVID-19) - China, 2020. CCDC Weekly 2020;2:113-122. https://cdn.onb.it/2020/03/COVID-19.pdf.pdf

17. Guarner J. Three emerging Coronaviruses in two decades: The story of SARS, MERS, and now COVID-19. Am J Clin Pathol 2020;153:420-421. https://doi.org/10.1093/ajcp/aqaa029

18. Kannan S, Ali PSS, Sheeza A, Hemalatha K. COVID-19 (Novel Coronavirus 2019) recent trends. Eur Rev Med Pharmaco 2020;24:2006-2011. https://www.europeanreview.org/wp/wp-content/uploads/2006-2011.pdf

19. Xu X, Chen P, Wang J, Feng J, Zhou H, Li X, Zhong W, Hao P. Evolution of the novel coronavirus from the ongoing Wuhan outbreak and modeling of its spike protein for risk of human transmission. Sci. China Life Sci. 2020;63:457460.https://doi.org/10.1007/s11427-020-1637-5

20. Wang L, Wang Y, Ye D, Liu Q. A review of the 2019 novel coronavirus (COVID-19) based on current evidence. Int J Antimicrob Agents 2020. https://doi.org/10.1016/j.ijantimicag.2020.105948

21. Fu Y, Cheng Y, Wu Y. Understanding SARS-CoV-2-mediated inflammatory responses: From mechanisms to potential therapeutic tools. Virol Sin 2020. https://doi.org/10.1007/s12250-020-00207-4

22. Zhao Y, Zhao Z, Wang Y, Zhou Y, Ma Y, Zuo W. Single-cell RNA expression profiling of ACE2, the putative receptor of Wuhan 2019-nCov. bioRxiv 2020. https://doi.org/10.1101/2020.01.26.919985

23. Sun P, Lu X, Xu C, Sun W, Pan B. Understanding of COVID-19 based on current evidence. J Med Virol 2020. https://doi.org/10.1002/jmv.25722

24. Zhang H, Penninger JM, Li Y, Zhong N, Slutsky AS. Angiotensin-converting enzyme 2 (ACE2) as a SARS-CoV-2 receptor: molecular mechanisms and potential therapeutic target. Intensive Care Med 2020;46:586-590. https://doi.org/10.1007/s00134-020-05985-9

25. Article

Geiger MJ. COVID-19, Influenza and cardiovascular disease - what is known? 2020. https://www.iconplc.com/insights/blog/2020/03/19/covid-19-influenza-andcardiovascular-disease/

26. Article

Pass W. COVID-19: Extra caution needed for patients with diabetes. 2020. https://www.the-hospitalist.org/hospitalist/article/219144/diabetes/covid-19-extracaution-needed-patients-diabetes

27. WHO https://www.who.int/health-topics/diabetes\#tab=tab_1

28. Saeedi P, Salpea P, Karuranga S, Petersohn I, Malanda B, Gregg EW, Unwin N, Wild SH, Williams R. Mortality attributable to diabetes in 20-79 years old adults, 2019 estimates: Results from the International Diabetes Federation Diabetes Atlas, $9^{\text {th }}$ edition. Diabetes Res Clin 2020. https://doi.org/10.1016/j.diabres.2020.108086

29. Liu Y, Sun W, Li J, Chen L, Wang Y, Zhang L, Yu Li. Clinical features and progression of acute respiratory distress syndrome in coronavirus disease 2019. medRxiv 2020. https://doi.org/10.1101/2020.02.17.20024166

30. Leung C. Clinical features of deaths in the novel coronavirus epidemic in China. Rev Med Virol 2020. https://doi.org/10.1002/rmv.2103

31. Wang S, Chen Z, Lin Y, Lin L, Lin Q, Fang S, Shi Y, Zhuang X, Ye Y, Wang T, Zhang H, Shao C. Epidemical and clinical characteristics of 165 patients infected with 
SARS-CoV-2 in Fujian Province, China. Available at SSRN (Preprints with The Lancet) 2020. https://doi.org/10.2139/ssrn.3551402

32. Pal R, Bhansali A. COVID-19, Diabetes Mellitus and ACE2: The conundrum. Diabetes Res Clin 2020. https://doi.org/10.1016/j.diabres.2020.108132

33. Fang L, Karakiulakis G, Roth M. Are patients with hypertension and diabetes mellitus at increased risk for COVID-19 infection? Lancet Respir Med 2020;8. https://doi.org/10.1016/S2213-2600(20)30116-8

34. Zhou J, Tan J. Diabetes patients with COVID-19 need better blood glucose management in Wuhan, China. Metab Clin Exp 2020;107:154216. https://doi.org/10.1016/j.metabol.2020.154216

35. Hill MA, Mantzoros C, Sowers JR. COVID-19 in patients with Diabetes. Metabo Clin Exp 2020;154217. https://doi.org/10.1016/j.metabol.2020.154217

36. Grossman E, Messerli FH. Hypertension and Diabetes. Adv Cardiol 82-2008;106. https://doi.org/10.1159/000115189

37. Lago RM, Singh PP, Nesto RW. Diabetes and Hypertension. Nat Rev Endocrinol 2007;3:667. https://doi.org/10.1038/ncpendmet0638

38. Chen X, Hu W, Ling J, Mo P, Zhang Y, Jiang Q, Ma Z, Cao Q, Deng L, Song S, Zheng R, Gao S, Ke H, Gui X, Lundkvist A, Li J, Lindahl JF, Xiong Y. Hypertension and Diabetes delay the viral clearance in COVID-19 patients. medRxiv 2020. https://doi.org/10.1101/2020.03.22.20040774

39. Pinto BGG, Oliveira AER, Singh Y, Jimenez L, Gonçalves ANA, Ogava RLT, Creighton R, Peron JPS, Nakaya HI. ACE2 expression is increased in the lungs of patients with comorbidities associated with severe COVID-19. medRxiv 2020. https://doi.org/10.1101/2020.03.21.20040261

40. Wnag J, Luo Q, Chen R, Chen T, Li J. Susceptibility analysis of COVID-19 in smokers based on ACE2. Preprints 2020;2020030078. https://doi.org/10.20944/preprints202003.0078.v1

41. Vardavas CI, Nikitara K. COVID-19 and smoking: A systematic review of the evidence. Tob Induc Dis 2020;18:20. https://doi.org/10.18332/tid/119324

42. Huang C, Wang Y, Li X, Ren L, Zhao J, Hu Y, et al. Clinical features of patients infected with 2019 novel coronavirus in Wuhan, China. The Lancet 2020;395:497506. https://doi.org/10.1016/S0140-6736(20)30183-5

43. Zhang J, Dong X, Cao Y, Yuan Y, Yang Y, Yan Y, et al. Clinical characteristics of 140 patients infected with SARS-CoV-2 in Wuhan, China. Allergy 2020. https://doi.org/10.1111/all.14238

44. Zhou F, Yu T, Du R, Fan G, Liu Y, Liu Z, et al. Clinical course and risk factors for mortality of adult inpatients with COVID-19 in Wuhan, China: A retrospective cohort study. The Lancet 2020;395:1054-1062. https://doi.org/10.1016/S01406736(20)30566-3

45. Shu L, Wang X, Li M, Chen X, Shi L, Wu M, et al. Clinical characteristics of 545 cases confirmed COVID-19 in Wuhan Stadium Cabin Hospital. Available at SSRN 2020. https://doi.org/10.2139/ssrn.3552844

46. Guan W, Ni Z, Hu Y, Liang W, Ou C, He C, He J, Liu L, et al. Clinical characteristics of coronavirus disease 2019 in China. N Engl J Med 2020. https://doi.org/10.1056/NEJMoa2002032

47. Cai H. Sex difference and smoking predisposition in patients with COVID-19. Lancet Respir Med 2020;8:PE20.https://doi.org/10.1016/S2213-2600(20)30117-X

48. Brake SJ, Barnsley K, Lu W, McAlinden KD, Eapen MS, Sohal SS. Smoking upregulates angiotensin-converting enzyme-2 receptor: A potential adhesion site for 
novel coronavirus SARS-CoV-2 (Covid-19). J Clin Med 2020;9:841. https://doi.org/10.3390/jcm903841

49. Olds JL, Kabbani N. Is nicotine exposure linked to cardiopulmonary vulnerability to COVID-19 in the general population? FEBS J 2020.https://doi.org/10.1111/febs.15303

50. Lippi G, Henry BR. Chronic obstructive pulmonary disease is associated with severe coronavirus disease 2019 (COVID-19). Respir Med 2020;105941. https://doi.org/10.1016.j.rmed.2020.105941

51. Caramelo F, Ferreira N, Oliveiros B. Estimation of risk factors for COVID-19 mortality - preliminary results. medRxiv 2020. https://doi.org/10.1101/202002.24.20027268

52. Inciardi RM, Lupi L, Zaccone G, Italia L, Raffo M, Tomasoni D, Cani DS, Cerini M, et al. (2020) Cardiac involvement in a patient with Coronavirus Disease 2019 (COVID-19). JAMA Cardiol 2020. https://doi.org/10.1001/jamacardio.2020.1096

53. Chen C, Chen C, Yan JT, Zhou N, Zhao JP, Wang DW. Analysis of myocardial injury in patients with COVID-19 and association between concomitant cardiovascular diseases and severity of COVID-19. Europe PMC 2020. https://doi.org/10.3760/cma.j.cn112148-20200225-00123

54. Zheng Y, Ma Y, Zhang J, Xie X. COVID-19 and the cardiovascular system. Nat Rev Cardiol 2020. https://doi.org/10.1038/s41569-020-0360-5

55. Peng YD, Meng K, Guan HQ, Leng L, Zhu RR, Wang BY, He MA, Cheng LX, Huang K, Zeng QT. Clinical characteristics and outcomes of 112 cardiovascular $\begin{array}{llll}\text { disease patients infected } 2020 . & \end{array}$ https://doi.org/10.3760/cma.j.cn112148-20200220-00105

56. Mao L, Wang M, Chen S, He Q, Chang J, Hong C, Zhou Y, Wang D, Miao X, Hu Y, Li Y, Jin H, HU B. Neurological manifestations of hospitalized patients with COVID19 in Wuhan, China: A retrospective case series study. Lancet Neurol 2020. https://doi.org/10.2139/ssrn.3544840

57. Li Y, Bai W, Hashikawa T. The neuroinvasive potential of SARS-CoV2 may play a role in the respiratory failure of COVID-19 patients. J Med Virol 2020. https://doi.org/10.1002/jmv.25728

58. Cheng Y, Luo R, Wang K, Zhang M, Wang Z, Dong L, Li J, Yao Y, Ge S, Xu G. Kidney impairment is associated with in-hospital death of COVID-19 patients. medRxiv 2020. https://doi.org/10.1101/2020.02.18.20023242

59. Li Z, Wu M, Yao J, Guo J, Liao X, Song S, Li J, Duan G, et al. Caution on kidney dysfunctions of COVID-19 patients. Lancet Infect Dis 2020. https://doi.org/10.2139/ssrn.3559601

60. Perico L, Benigni A, Remuzzi G. Should COVID-19 concern nephrologists? Why and to what extent? The emerging impasse of Angiotensin Blockade. Nephron 2020. https://doi.org/10.1159/000507305

61. Wu J, Liu J, Zhao X, Liu C, Wang W, Wang D, Xu W, Zhang C, Yu J, Jiang B, et al. Clinical characteristics of imported cases of coronavirus disease 2019 (COVID-19) in Jiangsu Province: A multicenter descriptive study. Clin Infect Dis 2020;ciaa199. https://doi.org/10.1093/cid/ciaa199

62. Yang W, Cao Q, Qin L, Wang X, Cheng Z, Pan A, Dai J, Sun Q, Zhao F, Qu J, Yan F. Clinical characteristics and imaging manifestations of the 2019 novel coronavirus disease (COVID-19): A multi-center study in Wenzhou city, Zhejiang, China. J Infection 2020;80:388-393. https://doi.org/10.1016/j.jinf.2020.02.016 
63. Wang L, Wang Y, Ye D, Liu Q. A review of the 2019 novel coronavirus (COVID-19) based on current evidence. Int J Antimicrob Agents 2020;105948. https://doi.org/10.1016/j.ijantimicag.2020.105948

64. Hu Y, Shen L, Xu Z, Zhou J, Zhou H. SARS-CoV-2 may persist in digestive tract $\begin{array}{llll}\text { longer than tract. } & \text { Preprints }\end{array}$ https://doi.org/10.20944/preprints202002.0354.v1

65. Mao R, Liang J, Shen J, Ghosh S, Zhu L, Yang H, Wu K, Chen M. Implications of COVID-19 for patients with pre-existing digestive diseases. Lancet Gastro enterol 2020. https://doi.org/10.1016/S2468-1253(20)30076-5

66. WHO https://www.who.int/news-room/fact-sheets/detail/tuberculosis

67. Ayebare RR, Flick R, Okware S, Bodo B, Lamorde M. Adoption of COVID-19 triage strategies for low-income settings. Lancet Respir Med 2020;8:PE22. https://doi.org/10.1016/S2213-2600(20)30114-4

68. Boffa J, Mhlaba T, Sulis G, Moyo S, Sifumba Z, Pai M, Daftary A. COVID-19 and tuberculosis in South Africa: A dangerous combination. S Afr Med J 2020. https://doi.org/10.7196/SAMJ.2020.v110i5.14747

69. WHO https://www.who.int/news-room/fact-sheets/detail/hiv-aids

70. Zhu F, Cao Y, Xu S, Zhou M. Co-infection of SARS-CoV-2 and HIV in a patient in Wuhan city, China. J Med Virol 2020. https://doi.org/10.1002/jmv.25732

71. Paintsil E (2020) COVID-19 threatens health systems in sub-Saharan Africa: the eye of the crocodile. J Clin Invest. https://doi.org/10.1172/JCI138493

72. Yang G, Zhang H, Yang Y. Challenges and countermeasures of integrative cancer therapy in the epidemic of COVID-19. Integr Cancer Ther 2020. https://doi.org/10.1177/1534735420912811

73. Kutikov A, Weinberg DS, Edelman MJ, Horwitz EM, Uzzo RG, Fisher RI. A War on two fronts: Cancer care in the time of COVID-19. Ann Intern Med 2020. https://doi.org/10.7326/M20-1133

74. Liang W, Guan W, Chen R, Wang W, Li J, Xu K, Li C, Ai Q, et al. Cancer patients in SARS-CoV-2 infection: a nationwide analysis in China. Lancet Oncol 2020;21:P335337. https://doi.org/10.1016/S1470-2045(20)30096-6

75. Zhang L, Zhu F, Xie L, Wang C, Wang J, Chen R, Jia P, Guan HQ, et al. Clinical characteristics of COVID-19-infected cancer patients: A retrospective case study in three hospitals within Wuhan, China. Ann Oncol 2020. https://doi.org/10.1016/j.annonc.2020.03.296

76. Xia Y, Jin R, Zhao J, Li W, Shen H. Risk of COVID-19 for patients with cancer. Lancet Oncol 2020;21:e180. https://doi.org/10.1016/S1470-2045(20)30150-9

77. Wei W, Jiang H, Chen W, Zhou Y, Guo S, Zhong G, Zhou H, Wang S, et al. How should we implement radiotherapy for cancer patients in China during the endemic period of COVID-19? Radiother Oncol 2020;147:P100-102. https://doi.org/10.1016/j.radonc.2020.03.016

78. Salako O, Okunade K, Allsop M, Habeebu M, Toye M, Oluyede G, Fagbenro G, Salako B. Upheaval in cancer care during the COVID-19 outbreak. Ecancermedicalscience 2020;14:ed97. https://doi.org/10.3332/ecamcer.2020.ed97

79. Hanna TP, Evans GA, Booth CM. Cancer, COVID-19 and the precautionary principle: prioritizing treatment during a global pandemic. Nat Rev Clin Oncol 2020. https://doi.org/10.1038/s41571-020-0362-6 
80. Huang J, Lin H, Wu Y, Fang Y, Kumar R, Chen G, Lin S. COVID-19 in posttransplantation patients - report of two cases. AmJ Transplant 2020. https://doi.org/10.1111/ajt.15896

81. Li F, Cai J, Dong N. First cases of COVID-19 in heart transplantation from China. J $\begin{array}{lll}\text { Heart Lung } & \text { Transpl }\end{array}$ https://www.jhltonline.org/pb/assets/raw/Health\%20Advance/journals/healun/First_C ases of COVID-19 in Heart Transplantation_From_China (1).pdf

82. Qin J, Wang H, Qin X, Zhang P, Zhu L, Cai J, Yuan Y, Li H. Perioperative presentation of COVID-19 disease in a liver transplant recipient. Hepatology 2020. https://doi.org/10.1002/hep.31257

83. Guillen E, Pineiro GJ, Revuelta I, Rodriguez D, Bodro M, Moreno A, Campistol JM, Diekmann F. Case report of COVID-19 in a kidney transplant recipient: Does immunosuppression alter the clinical presentation? AmJ Transplant 2020. https://doi.org/10.1111/ajt.15874

84. Liang H, Acharya G. Novel coronavirus disease (COVID-19) in pregnancy: What clinical recommendations to follow? Acta Obstet Gynecol Scand 2020;99:439-442. https://doi.org/10.1111/aogs.13836

85. Dashraath P, Jeslyn WJL, Karen LMX, Min LL, Sarah L, Biswas A, Choolani MA, Mattar C. Coronavirus Disease 2019 (COVID-19) Pandemic and Pregnancy. Am J Obstet Gynecol 2020. https://doi.org/10.1016/j.ajog.2020.03.021

86. Qiao J. What are the risks of COVID-19 infection in pregnant women? Lancet 2020;395:P760-762. https://doi.org/10.1016/S0140-6736(20)30365-2

87. Qiu H, Wu J, Hong L, Luo Y, Song Q, Chen D. Clinical and epidemiological features of 36 children with coronavirus disease 2019 (COVID-19) in Zhejiang, China: an observational cohort study. Lancet Infect Dis 2020. https://doi.org/10.1016/S14733099(20)30198-5

88. Sinha IP, Harwood R, Semple MG, Hawcutt DB, Thursfield R, Narayan O, Kenny SE, Viner R, et al. COVID-19 infection in children. Lancet Respir Med 2020. https://doi.org/10.1016/S2213-2600(20)30152-1

89. $\mathrm{Wu} \mathrm{Z,} \mathrm{McGoogan} \mathrm{JM.} \mathrm{Characteristics} \mathrm{if} \mathrm{and} \mathrm{important} \mathrm{lessons} \mathrm{from} \mathrm{the} \mathrm{Coronavirus}$ Disease 2019 (COVID-19) outbreak in China. JAMA 2020;323:1239-1242. https://doi.org/10.1001/jama.2020.2648

90. Peron JPS, Nakaya H. Susceptibility of the elderly to SARS-CoV-2 infection: ACE-2 overexpression, shedding and antibody-dependent enhancement (ADE). Preprints 2020. https://doi.org/10.20944/preprints202003.0400.v1 